\title{
Pengaruh Kebijakan Pembatasan Sosial Berskala Besar (PSBB) terhadap Kinerja Penyuluh Pertanian di Provinsi DKI Jakarta
}

\author{
Ayu Puspita Sari ${ }^{1}$, Sugihardjo $^{2}$ dan Widiyanto ${ }^{3}$
}

Fakultas Pertanian, Universitas Sebelas Maret, Surakarta, Indonesia ${ }^{\mathbf{1 2}}$

Email: ayupitasari@student.uns.ac.id, sugihardjo@staff.uns.ac.id, widiyanto@staff.uns.ac.id

\begin{tabular}{l}
\hline \multicolumn{1}{c}{ Artikel info } \\
Artikel history: \\
Diterima : $15-05-2021$ \\
Direvisi : $10-06-2021$ \\
Disetujui : $15-06-2021$
\end{tabular}

Keywords:

performance; agricultural extension worker; $P S B B$

Kata Kunci:

kinerja; penyuluh pertanian; PSBB

\begin{abstract}
:
COVID-19 was first designated a pandemic by the WHO in February 2020 and has spread to at least 124 countries around the world. COVID-19 entered Indonesia on March 2, 2020, then spread widely throughout Indonesia. The COVID-19 pandemic in Indonesia is predicted to affect the existence of the agricultural sector if its development becomes more widespread. This study aims to (1) Analyze the performance of agricultural extensionists in DKI Jakarta Province during the implementation of PSBB; (2) Know the factors that may affect the performance of agricultural extensionists in DKI Jakarta Province during the implementation of PSBB; (3) Knowing the influence between internal and external factors of agricultural extension to the performance of agricultural extensionists during the implementation of PSBB. The method used in research is a quantitative method with explantation. The location of the research is determined intentionally (purposive) namely in the Province of DKI Jakarta. The sampling method is determined by sensus technique. The data analysis conducted in this study is to use descriptive analysis and multiple linear regression tests. The results of this study showed that the performance of agricultural extensionists in DKI Jakarta Province during the implementation of PSBB is in the category of both with the implementation in the category of sufficient and evaluation and reporting in the category are very good. The performance of agricultural extension workers in DKI Jakarta province is influenced by age, working period, education, training, availability of infrastructure facilities, and working environment conditions by $52.5 \%$.
\end{abstract}

\begin{abstract}
Abstrak:
COVID-19 pertama kali ditetapkan sebagai pandemi oleh WHO pada Februari 2020 dan setidaknya sudah menyebar ke 124 negara di dunia. COVID-19 masuk ke Indonesia pada 2 Maret 2020, kemudian menyebar luas di hampir seluruh wilayah Indonesia. Pandemi COVID-19 yang terjadi di Indonesia diprediksi akan mempengaruhi eksistensi sektor pertanian apabila perkembangannya semakin meluas. Penelitian ini bertujuan untuk (1) Menganalisis kinerja penyuluh pertanian di Provinsi DKI Jakarta selama diberlakukannya Pembatasan Sosial Berskala Besar; (2) Mengetahui faktorfaktor yang dapat mempengaruhi kinerja penyuluh pertanian di Provinsi DKI Jakarta selama diberlakukannya Pembatasan Sosial Berskala Besar; (3) Mengetahui pengaruh antara faktor internal dan eksternal penyuluh pertanian terhadap kinerja penyuluh pertanian selama diberlakukannya Pembatasan Sosial Berskala Besar. Metode yang digunakan dalam penelitian adalah metode kuantitatif dengan eksplanatori. Lokasi penelitian ditentukan secara sengaja (purposive) yaitu di Provinsi DKI Jakarta. Metode pengambilan sampel ditentukan dengan teknik sensus. Analisis data yang dilakukan pada penelitian ini adalah dengan menggunakan analisis deskriptif dan uji regresi linear berganda. Hasil penelitian menunjukan bahwa kinerja penyuluh pertanian di Provinsi DKI Jakarta selama diberlakukannya PSBB
\end{abstract}


berada pada kategori baik dengan pelaksanaan dalam kategori cukup dan evaluasi dan pelaporan dalam kategori sangat baik. Kinerja penyuluh pertanian Provinsi DKI Jakarta dipengaruhi oleh umur, masa kerja, pendidikan, pelatihan, ketersediaan sarana prasarana, dan kondisi lingkungan kerja sebesar 52,5\%.

Coresponden author: Ayu Puspita Sari Email: ayupitasari@student.uns.ac.id artikel dengan akses terbuka dibawah lisensi

CC BY SA 2021

\section{Pendahuluan}

COVID-19 pertama kali ditetapkan sebagai pandemi oleh WHO pada Februari 2020 dan setidaknya sudah menyebar ke 124 negara di dunia (Emanuel et al., 2020). COVID-19 masuk ke Indonesia pada 2 Maret 2020, kemudian menyebar luas di hampir seluruh wilayah Indonesia. Pandemi COVID-19 yang masuk ke Indonesia mulai awal 2020 sudah berdampak sangat besar bagi kehidupan masyarakat. Pandemi mengakibatkan lumpuhnya roda perekonomian dunia termasuk Indonesia. Kegiatan ekspor impor terhambat karena adanya kebijakan lockdown di beberapa negara dan mereka juga mengupayakan agar cadangan pangan mereka cukup untuk bertahan di masa pandemi.

Berdasarkan data dari Satuan Tugas Penanganan COVID-19 pada 11 September 2020, Provinsi DKI Jakarta menjadi provinsi dengan kasus positif COVID-19 tertinggi di Indonesia yaitu sebesar 51.635 atau 24,5\% dari total kasus di Indonesia. Provinsi DKI Jakarta sebagai salah satu wilayah dengan angka penularan COVID-19 tertinggi berupaya untuk mencegah penyebarannya dengan menerapkan Pembatasan Sosial Berskala Besar. Kebijakan ini mulai diberlakukan pada 10 April 2020 di Provinsi DKI Jakarta berdasarkan Peraturan Gubernur Daerah Provinsi DKI Jakarta No. 33 Tahun 2020 (Situmeang, 2020). PSBB dilakukan dalam bentuk pembatasan aktivitas luar rumah oleh warga yang berdomisili atau yang berkegiatan di Provinsi DKI Jakarta. Kebijakan tersebut memberikan dampak dalam berbagai sektor, seperti pendidikan, perekonomian, dan juga berdampak pada kegiatan penyuluhan pertanian yang dilakukan oleh penyuluh pertanian di Provinsi DKI Jakarta.

Pandemi COVID-19 yang terjadi di Indonesia diprediksi akan mempengaruhi eksistensi sektor pertanian apabila perkembangannya semakin meluas. Terdapat beberapa dampak yang mungkin akan mempengaruhi sektor pertanian apabila penyakit ini masih terus berkembang. Pertama, tidak normalnya pasar dan transaksi sehingga akan mempengaruhi stabilitas supply dan demand barang dan jasa serta harga mungkin akan meningkat. Kedua, melambatnya rantai pasokan sehingga dapat mengakibatkan kekurangan produk-produk pertanian. Ketiga, kesehatan petani terancam karena usia petani relatif lebih tua dibanding dengan pekerja lain sehingga jika penyakit ini meluas dan menyerang petani maka akan memperburuk produksi pangan (Pusat Penelitian dan Pengembangan Perkebunan, 2020). Pandemi juga mempengaruhi kerja petani, menghambat kegiatan kelompok tani, dan kegiatan mobilisasi sumber daya (Sasakawa Africa Association, 2020). Berbagai dampak yang mungkin ditimbulkan oleh COVID-19 terhadap sektor pertanian perlu diatasi oleh pemerintah agar ketersediaan pangan tetap terjamin. 
Pandemi yang sedang terjadi di Indonesia mengakibatkan kegiatan penyuluhan pertanian terhambat. Penyuluh pertanian kesulitan dalam memberikan penyuluhan dan pendampingan pada kondisi pembatasan yang sedang diberlakukan saat ini. Akses pelatihan kepada petani terhambat karena minimnya dukungan teknis terkait. Saat kondisi PSBB, baik penyuluh maupun petani harus dapat mengikuti kegiatan penyuluhan dengan perubahan dari penyuluhan tradisional menjadi penyuluhan yang lebih modern.

Menurut Peraturan Menteri Pertanian Republik Indonesia Nomor 03/Permentan/SM.200/1/2018 tentang Pedoman Penyelenggaraan Penyuluhan Pertanian dijelaskan bahwa sistem penyuluhan pertanian adalah seluruh rangkaian pengembangan kemampuan pengetahuan, keterampilan, serta sikap pelaku utama dan pelaku usaha melalui penyuluhan (Muharsini \& Tiesnamurti, 2017). Penyuluh Pertanian Provinsi DKI Jakarta bersifat polivalen, artinya penyuluh dituntut dapat melakukan penyuluhan dengan konteks pertanian secara luas. Menurut (Arwati, 2018) pertanian dalam arti luas meliputi pertanian rakyat, perkebunan, kehutanan, peternakan, dan perikanan. Penyuluh dituntut untuk dapat mengerti dan memberikan penyuluhan sesuai dengan program dan kebijakan yang berlaku. Selama diberlakukannya PSBB, penyuluh pertanian harus dapat beradaptasi untuk tetap dapat melaksanakan kegiatan penyuluhan pertanian.

Berdasarkan Peraturan Menteri Pertanian Nomor 91 Tahun 2013 tentang Pedoman Evaluasi Kinerja Penyuluh Pertanian, kinerja penyuluh pertanian dinilai berdasarkan tiga indikator, yaitu persiapan penyuluhan pertanian, pelaksanaan penyuluhan pertanian, dan evaluasi dan pelaporan penyuluhan pertanian. Rahmawati dkk (2019) menjelaskan bahwa penyuluh pertanian mempunyai tugas pokok dan fungsi yang perlu dilakukan untuk mencapai kinerja yang baik. Penyuluh yang berkinerja baik dapat memposisikan dirinya sebagai motivator, edukator, fasilitator dan dinamisator yang berdampak pada perubahan perilaku petani dalam berusaha tani.

Faktor-faktor yang mempengaruhi kinerja penyuluh pertanian selama masa pandemi COVID-19 adalah karakteristik penyuluh pertanian dan faktor eksternal. Karakteristik penyuluh yang berpengaruh terhadap kinerja penyuluhan adalah usia penyuluh, tingkat pendidikan penyuluh, dan banyaknya pelatihan di bidang pertanian. Faktor eksternal yang berpengaruh terhadap kinerja penyuluhan adalah sarana dan prasarana penunjang kegiatan penyuluhan dan kondisi lingkungan kerja penyuluh pertanian (Wibowo dan Haryanto, 2020). Berdasarkan penelitian yang dilakukan oleh Wibowo dan Haryanto (2020), maka penelitian ini dilakukan untuk meneliti kinerja penyuluh pertanian di Provinsi DKI Jakarta selama diberlakukannya PSBB dan menganalisis faktor yang dapat mempengaruhi kinerja selama PSBB diterapkan. Kebaruan dalam penelitian ini terletak pada lokasi penelitian, faktor-faktor kinerja, dan situasi yaitu pada saat PSBB.

Penyuluh pertanian merupakan ujung tombak dalam keberlangsungan dan kemajuan pertanian di Indonesia (Purwatiningsih et al., 2018). Penyuluh memiliki peran penting bagi pemenuhan kebutuhan pangan di seluruh Indonesia, apalagi di masa pandemi COVID-19 seperti saat ini dimana negara sulit untuk melakukan impor pangan. Penyuluh pertanian harus dapat memastikan bahwa usaha pertanian tetap berjalan ditengah pandemi seperti saat ini karena kebutuhan pangan masyarakat sangat bergantung pada pertanian. Penyuluh pertanian yang memiliki fungsi sebagai motivator, fasilitator, maupun edukator merupakan tumpuan bagi Indonesia untuk mendampingi petani dalam upaya pemenuhan pasokan pangan. Berdasarkan uraian di atas, maka penelitian ini bertujuan untuk: (1) menganalisis kinerja penyuluh pertanian di Provinsi DKI Jakarta selama diberlakukannya PSBB, (2) mengetahui 
faktor-faktor yang dapat mempengaruhi kinerja penyuluh pertanian di Provinsi DKI Jakarta selama diberlakukannya PSBB, (3) mengetahui pengaruh antara faktor internal dan eksternal penyuluh pertanian terhadap kinerja penyuluh pertanian selama diberlakukannya PSBB.

\section{Metode Penelitian}

Metode penelitian yang digunakan dalam penelitian ini adalah kuantitatif eksplanatori. Penelitian kuantitatif umumnya berfokus pada pengukuran realitas sosial (Duli, 2019). Explanatory research adalah penelitian yang bertujuan untuk hubungan-hubungan kausal antar variabel melalui pengujian hipotesa (Effendi \& Singarimbun, 1995). Penentuan lokasi penelitian dilakukan secara sengaja (purposive) yaitu berdasarkan pertimbangan tertentu yang disesuaikan dengan tujuan penelitian (Effendi \& Singarimbun, 1995). Lokasi penelitian yang dipilih adalah Provinsi DKI Jakarta. Provinsi DKI Jakarta dipilih karena merupakan salah satu Provinsi dengan angka penyebaran COVID-19 yang sangat tinggi di Indonesia.

Populasi dalam penelitian ini adalah seluruh penyuluh pertanian PNS yang bertugas di Provinsi DKI Jakarta. Penyuluh pertanian tersebar di tujuh wilayah kerja, yaitu wilayah kerja provins, lima kota administrasi dan satu kabupaten administrasi dengan rincian sebagai berikut:

Tabel 1. Populasi Penelitian di Provinsi DKI Jakarta

\begin{tabular}{|c|c|c|}
\hline No & Lokasi Kerja & $\begin{array}{c}\text { Jumlah Penyuluh Pertanian } \\
\text { PNS }\end{array}$ \\
\hline 1 & Provinsi DKI Jakarta & 1 \\
\hline 2 & Kota Jakarta Pusat & 10 \\
\hline 3 & Kota Jakarta Selatan & 7 \\
\hline 4 & Kota Jakarta Barat & 6 \\
\hline 5 & Kota Jakarta Utara & 5 \\
\hline 6 & Kota Jakarta Timur & 9 \\
\hline 7 & Kabupaten Kepulauan Seribu & 3 \\
\hline & JUMLAH & 41 \\
\hline
\end{tabular}

Sumber: Dinas Ketahanan Pangan, Kelautan, dan Pertanian Provinsi DKI Jakarta, 2020

Teknik pengambilan sampel yang digunakan dalam penelitian ini adalah teknik sensus (total sampling). Menurut (Sugiyono, 2018) sensus (total sampling) adalah teknik pengambilan sampel dimana seluruh anggota populasi dijadikan sampel. Penelitian dengan populasi di bawah 100 sebaiknya dilakukan dengan sensus, sehingga seluruh anggota populasi tersebut dijadikan sampel sebagai responden pemberi informasi. Sampel dari penelitian ini adalah keseluruhan populasi, yaitu seluruh penyuluh pertanian PNS di Provinsi DKI Jakarta dengan tujuh wilayah kerja.

Sumber data yang digunakan dalam penelitian ini adalah sumber data primer dan sekunder dengan jenis data kuantitatif dan kualitatif. Pengumpulan data dilakukan dengan menggunakan beberapa teknik, yaitu dengan kuisioner (angket) wawancara, dan dokumentasi. Data dikumpulkan secara online melalui google form. Kinerja penyuluh pertaian di Provinsi DKI Jakarta dianalisis menggunakan analisis deskriptif. Sedangkan pengaruh antara faktor-faktor kinerja dengan kinerja penyuluh pertanian selama masa PSBB dianalisis menggunakan uji regresi linear berganda. 
Berdasarkan uraian perumusan masalah dan kerangka berpikir, maka hipotesis dalam penelitian ini adalah:

1. Diduga kinerja penyuluh pertanian di Provinsi DKI Jakarta baik saat diberlakukannya Kebijakan Pembatasan Sosial Berskala Besar.

2. Diduga terdapat pengaruh yang signifikan antara umur, masa kerja, tingkat pendidikan formal, pelatihan, ketersediaan sarana prasarana, dan kondisi lingkungan kerja dengan kinerja penyuluh pertanian Provinsi DKI Jakarta selama diberlakukannya Kebijakan PSBB.

\section{$\widehat{\mathbf{Y}}=\mathbf{a}+\mathrm{b}_{1} \mathrm{X}_{1}+\mathrm{b}_{2} \mathrm{X}_{2}+\mathrm{b}_{3} \mathrm{X}_{3}+\mathrm{b}_{4} \mathrm{X}_{4}+\mathrm{b}_{5} \mathrm{X}_{5}+\mathrm{b}_{6} \mathrm{X}_{6}$}

Keterangan:

$\widehat{Y} \quad$ : Variabel dependen (kinerja penyuluh pertanian)

$\mathrm{X}_{1}$ : Umur

$\mathrm{X}_{2}$ : Masa kerja

$\mathrm{X}_{3}$ : Pendidikan formal

$\mathrm{X}_{4}$ : Pelatihan

$\mathrm{X}_{5}$ : Ketersediaan sarana dan prasarana

$\mathrm{X}_{6}$ : Kondisi lingkungan kerja

a : Konstanta

b : Koefisien regresi

Model regresi linear berganda dipilih untuk mengetahui seberapa besar pengaruh variable bebas terhadap variabel terikat baik secara parsial maupun bersama-sama. Sebelum model regresi digunakan untuk menguji hipotesis, maka terlebih dahulu dilakukan pengujian asumsi klasik yang meliputi uji multikolinearitas, uji heteroskedastisitas, dan uji normalitas. Langkah selanjutnya adalah pengujian hipotesis untuk mengetahui diterima atau tidaknya hipotesis yang diajukan menggunakan uji F dan uji t (Al Naggar et al., 2015).

\section{Hasil dan Pembahasan}

\section{Gambaran Umum}

Provinsi DKI Jakarta terdiri dari lima kota administasi dan satu kabupaten administasi dengan jumlah penduduk yang besar. Dalam pemenuhan kebutuhan pangan sehari-hari, DKI Jakarta mendapatkan pasokan dari daerah sekitar DKI Jakarta. Kondisi seperti ini membuat DKI Jakarta sangat rentan dalam ketahanan pangan.

Pertanian perkotaan di Jakarta memiliki keragaman fungsi dan keragaman bentuk spasial. Fungsi tradisional pertanian sebagai penyedia pangan masih bertahan. Hal ini ditunjukkan dengan aktivitas pertanian tanaman padi yang merupakan makanan pokok masih dapat ditemukan walaupun marjinal secara spasial. Fungsi-fungsi selain penyediaan pangan berkembang seiring dengan perkembangan kota. Di satu sisi, perkembangan kota menekan pertanian. Namun di sisi lain, perkembangan kota memungkinkan berkembangnya fungsifungsi selain penyediaan pangan yang memberikan nilai-nilai kekotaan yang baru tercipta di tengah-tengah dampak negatif urbanisasi seperti pemanasan kota, polusi, dan padatnya kota (Anggrahita \& Guswandi, 2018) Luas lahan pertanian di DKI Jakarta dapat dilihat pada Tabel 2 berikut.

Tabel 2. Luas Lahan Pertanian di Provinsi DKI Jakarta Tahun 2012-2017 


\begin{tabular}{ccccc}
\hline \hline Tahun & $\begin{array}{c}\text { Luas Ladang } \\
(\mathrm{Ha})\end{array}$ & $\begin{array}{c}\text { Luas } \\
\text { Tegal/Kebun } \\
(\mathrm{Ha})\end{array}$ & $\begin{array}{c}\text { Luas Sawah } \\
(\mathrm{Ha})\end{array}$ & Jumlah \\
\hline 2012 & 75 & 1.100 & 1.100 & 2.275 \\
2013 & 0 & 1.000 & 895 & 1.895 \\
2014 & 0 & 932 & 778 & 1.710 \\
2015 & 0 & 955 & 650 & 1.605 \\
2016 & 420 & 497 & 587 & 1.504 \\
2017 & 0 & 923,5 & 584,5 & 1.508 \\
\hline \hline
\end{tabular}

Sumber: Data Sekunder

Dalam upaya ketahanan pangan, Dinas Ketahanan Pangan, Kelautan, dan Pertanian DKI Jakarta bersama stakeholder terkait membuat Grand Desain Pertanian Perkotaan untuk menghijaukan seluruh wilayah DKI Jakarta. Wilayah yang dihijaukan antara lain gang, rumah susun, pinggir kali, dan sebagainya. Dalam mewujudkan Grand Desain tersebut, penyuluh pertanian memiliki andil yang sangat vital dalam keberhasilan program.

Tabel 3. Penyuluh Pertanian DKI Jakarta tahun 2020

\begin{tabular}{|c|c|c|c|c|c|c|}
\hline No & Provinsi & $\begin{array}{c}\text { Jumlah } \\
\text { PNS }\end{array}$ & $\begin{array}{c}\text { Jumlah } \\
\text { BPP }\end{array}$ & $\begin{array}{c}\text { Jumlah } \\
\text { Kecamat } \\
\text { an/Distric } \\
t\end{array}$ & $\begin{array}{c}\text { POSLUHDE } \\
\text { S }\end{array}$ & $\begin{array}{c}\text { Jumlah } \\
\text { PP } \\
\text { Swadaya }\end{array}$ \\
\hline 1 & Dinas Provinsi & 1 & - & - & - & - \\
\hline 2 & BPTP & 3 & - & - & - & - \\
\hline 3 & $\begin{array}{l}\text { Kota Jakarta } \\
\text { Utara }\end{array}$ & 7 & 1 & 6 & 7 & 3 \\
\hline 4 & $\begin{array}{l}\text { Kota Jakarta } \\
\text { Pusat }\end{array}$ & 10 & 1 & 8 & 8 & 16 \\
\hline 5 & $\begin{array}{l}\text { Kota Jakarta } \\
\text { Timur }\end{array}$ & 10 & 2 & 10 & 11 & 7 \\
\hline 6 & $\begin{array}{l}\text { Kota Jakarta } \\
\text { Barat }\end{array}$ & 8 & 1 & 8 & 8 & 12 \\
\hline 7 & $\begin{array}{l}\text { Kota Jakarta } \\
\text { Selatan }\end{array}$ & 10 & 1 & 10 & 12 & 20 \\
\hline 8 & $\begin{array}{l}\text { Kab. Kep. } \\
\text { Seribu }\end{array}$ & 3 & - & 2 & 2 & 3 \\
\hline & Jumlah & 52 & 6 & 44 & 48 & 61 \\
\hline
\end{tabular}

Sumber : Data Sekunder

Berdasarkan Tabel 3, dapat diketahui bahwa terdapat delapan penempatan penyuluh Provinsi DKI Jakarta yaitu di Dinas Provinsi, BPTP, Kota Jakarta Utara, Kota Jakarta Pusat, Kota Jakarta Timur, Kota Jakarta Barat, Kota Jakarta Selatan, dan Kabupaten Kepulauan Seribu. Provinsi DKI Jakarta memiliki 52 penyuluh PNS, 6 THL-TBPP (Tenaga Harian Lepas - Tenaga Bantu Penyuluh Pertanian), dan 61 penyuluh swadaya. Sebaran penyuluh PNS di DKI Jakarta yaitu satu orang di Dinas Provinsi, tiga orang di BPTP, tujuh orang di Kota Jakarta Utara, sepuluh orang di Kota Jakarta Pusat, sepuluh orang di Kota Jakarta 
Timur, delapan orang di Kota Jakarta Barat, sepuluh orang di Kota Jakarta Selatan, dan tiga orang di Kabupaten Kepulauan Seribu. Penyuluh swadaya DKI Jakarta tersebar di lima kota dan satu kabupaten di Provinsi DKI Jakarta dengan sebaran sebanyak tiga orang di Kota Jakarta Utara, 16 orang di Kota Jakarta Pusat, tujuh orang di Kota Jakarta Timur, 12 orang di Kota Jakarta Barat, 20 orang di Kota Jakarta Selatan, dan tiga orang di Kabupaten Kepulauan Seribu.

\section{Kinerja Penyuluh Pertanian Provinsi DKI Jakarta}

Kinerja merupakan tingkat pelaksanaan tugas yang dapat dicapai seseorang dengan menggunakan kemampuan yang ada dan batasan yang telah ditetapkan untuk mencapai tujuan organisasi. Kinerja penyuluh pertanian dalam memberdayakan petani adalah perilaku aktual yang diperagakan penyuluh sebagai kewajibannya mengemban tugas-tugas pemberdayaan yang diamanahkan kepadanya (Sutrisno, 2016). (Rahmawati et al., 2019) menjelaskan bahwa penyuluh pertanian mempunyai tugas pokok dan fungsi yang perlu dilakukan untuk mencapai kinerja yang baik. Penyuluh yang berkinerja baik dapat memposisikan dirinya sebagai motivator, edukator, fasilitator dan dinamisator yang berdampak pada perubahan perilaku petani dalam berusahatani. Kinerja dalam penelitian ini diukur berdasarkan indikator pelaksanaan dan evaluasi penyuluhan pertanian. Distribusi responden berdasarkan kinerja dapat dilihat pada Tabel 4 berikut.

Tabel 4. Distribusi Responden Berdasarkan Kinerja

\begin{tabular}{|c|c|c|c|c|}
\hline No & Kategori & Skor & Jumlah & Persentase (\%) \\
\hline 1. & Kurang & $15,00-18,50$ & 8 & 19,51 \\
\hline 2. & Cukup & $18,51-22,00$ & 10 & 24,40 \\
\hline 3. & Baik & $22,01-25,50$ & 12 & 29,27 \\
\hline 4. & Sangat Baik & $25,51-29,00$ & 11 & 26,82 \\
\hline \multicolumn{3}{|c|}{ JUMLAH } & 41 & 100,00 \\
\hline
\end{tabular}

Sumber: Analisis Data Primer

Berdasarkan Tabel 4 menjelaskan bahwa sebesar 19,51\% penyuluh berkinerja kurang, $24,40 \%$ penyuluh berkinerja cukup, $29,27 \%$ berkinerja baik, dan $26,82 \%$ penyuluh berkinerja sangat baik. Penelitian ini menunjukkan sebagian besar penyuluh pertanian memiliki kinerja yang baik dengan persentase sebesar $29,27 \%$ pada saat diberlakukannya PSBB. Penyuluh pertanian di Provinsi DKI Jakarta memiliki kinerja yang baik meskipun dalam kebijakan WFH dan WFO. (Bahua, 2016) menjelaskan bahwa penyuluh yang berkinerja baik dapat memposisikan dirinya sebagai motivator, edukator, fasilitator dan dinamisator yang berdampak pada perubahan perilaku petani dalam berusahatani. Penyuluh pertanian perlu memiliki berbagai kemampuan antara lain kemampuan berkomunikasi, berpengetahuan luas, bersikap mandiri dan mampu menempatkan dirinya sesuai dengan karakteristik petani.

\section{Faktor-Faktor yang Mempengaruhi kinerja Penyuluh Pertanian di Provinsi DKI} Jakarta Selama PSBB

a. Persamaan Regresi

$$
\begin{gathered}
\widehat{Y}=a+b_{1} X_{1}+b_{2} X_{2}+b_{3} X_{3}+b_{4} X_{4}+b_{5} X_{5}+b_{6} X_{6} \\
Y=-5,494+1,385 X_{1}-0,197 X_{2}+1,564 X_{3}+1,095 X_{4}+0,396 X_{5}+0,523 X_{6}
\end{gathered}
$$


Keterangan:

$\widehat{Y} \quad$ : Variabel dependen (kinerja penyuluh pertanian)

$\mathrm{X}_{1}$ : Umur

$\mathrm{X}_{2}$ : Masa kerja

$\mathrm{X}_{3}$ : Pendidikan formal

$\mathrm{X}_{4}$ : Pelatihan

$\mathrm{X}_{5}$ : Ketersediaan sarana dan prasarana

$\mathrm{X}_{6}$ : Kondisi lingkungan kerja

a : Konstanta

b : Koefisien regresi

b. Uji Simultan (Uji F)

Tabel 5. Hasil Uji Simultan

\begin{tabular}{lccccc}
\hline \hline \multicolumn{1}{c}{ Model } & $\begin{array}{c}\text { Sum of } \\
\text { Squares }\end{array}$ & $d f$ & $\begin{array}{c}\text { Mean } \\
\text { Square }\end{array}$ & F & Sig. \\
\hline Regression & 319,304 & 6 & 53,217 & 6,273 & 0,000 \\
Residual & 288,452 & 34 & 8,484 & & \\
Total & 607,756 & 40 & & & \\
\hline \hline
\end{tabular}

Sumber: Analisis Data Primer

Tabel 5 menunjukkan hasil uji simultan pada regresi linear berganda dengan melihat tabel ANOVA pada output SPSS. Hasil uji simultan pada tabel 5.13 menunjukkan nilai $p$ value pada kolom Sig. sebesar 0,000. Nilai $p$-value 0,000 lebih kecil dari signifikansi $(\alpha=$ 0,05) sehingga dapat disimpulkan bahwa variabel independen (umur, pengalaman, pendidikan, pelatihan, kondisi sarana prasarana, dan kondisi lingkungan kerja) secara bersama-sama memiliki pengaruh terhadap variabel dependen (kinerja penyuluh pertanian).

c. Uji Parsial (Uji t)

Tabel 6. Hasil Uji Parsial

\begin{tabular}{lcc}
\hline \hline \multicolumn{1}{c}{ Model } & Sig. & Keterangan \\
\hline Umur $\left(\mathrm{X}_{1}\right)$ & 0,110 & Tidak Signifikan \\
Masa Kerja $\left(\mathrm{X}_{2}\right)$ & 0,817 & Tidak Signifikan \\
Pendidikan $\left(\mathrm{X}_{3}\right)$ & 0,015 & Signifikan \\
Pelatihan $\left(\mathrm{X}_{4}\right)$ & 0,044 & Signifikan \\
Ketersediaan Sarana Prasarana $\left(\mathrm{X}_{5}\right)$ & 0,010 & Signifikan \\
Kondisi Lingkungan Kerja $\left(\mathrm{X}_{6}\right)$ & 0,023 & Signifikan \\
\hline \hline
\end{tabular}

Sumber: Analisis Data Primer

1) Pengaruh umur $\left(X_{1}\right)$ terhadap kinerja penyuluh pertanian

Hasil uji parsial pada Tabel 6 menunjukkan bahwa variabel umur secara parsial tidak berpengaruh nyata terhadap kinerja penyuluh pertanian di Provinsi DKI Jakarta. Hal ini dibuktikan dengan nilai $p$-value sebesar 0,110 lebih besar dari signifikansi $(\alpha=0,05)$. Tinggi atau tidaknya umur penyuluh tidak berpengaruh terhadap kinerja penyuluh pertanian. Hal ini diduga karena pembagian tugas pada penyuluh pertanian di Provinsi DKI Jakarta tidak berdasarkan usia. 
2) Pengaruh masa kerja $\left(X_{2}\right)$ terhadap kinerja penyuluh pertanian

Hasil uji parsial pada Tabel 6 menunjukkan bahwa variabel pengalaman secara parsial tidak berpengaruh nyata terhadap kinerja penyuluh pertanian di Provinsi DKI Jakarta. Hal ini dibuktikan dengan nilai $p$-value sebesar 0,817 lebih besar dari signifikansi $(\alpha=0,05)$.

Kondisi demikian dikarenakan standar mengukur pengalaman pada penelitian ini adalah dengan mengukur lamanya penyuluh bekerja sebagai PNS. Hasil penelitian menunjukkan bahwa semakin tinggi masa kerja penyuluh sebagai PNS maka semakin rendah kinerja penyuluh.

3) Pengaruh pendidikan $\left(X_{3}\right)$ terhadap kinerja penyuluh pertanian

Hasil uji parsial pada Tabel 6 menunjukkan bahwa variabel pendidikan secara parsial berpengaruh nyata terhadap kinerja penyuluh pertanian di Provinsi DKI Jakarta. Hal ini dibuktikan dengan nilai $p$-value sebesar 0,015 lebih kecil dari signifikansi $(\alpha=0,05)$.

Hipotesis pada penelitian ini yang menyatakan bahwa pendidikan dapat mempengaruhi kinerja penyuluh pertanian dinyatakan diterima.

Pendidikan formal yang ditempuh oleh penyuluh pertanian merupakan salah satu faktor internal yang penting bagi penyuluh pertnian. Pendidikan formal yang dimiliki penyuluh dapat berfungsi sebagai salah satu syarat untuk kenaikan jabatan penyuluh pertanian. Pendidikan formal juga ditujukan untuk meningkatkan sikap, kemampuan, dan keterampilan penyuluh dalam menjalankan pekerjaan dan menyelesaikan berbagai masalah yang dihadapi dalam pekerjaannya.

4) Pengaruh pelatihan $\left(\mathrm{X}_{4}\right)$ terhadap kinerja penyuluh pertanian

Hasil uji parsial pada Tabel 6 menunjukkan bahwa variabel pelatihan secara parsial berpengaruh nyata terhadap kinerja penyuluh pertanian di Provinsi DKI Jakarta. Hal ini dibuktikan dengan nilai $p$-value sebesar 0,044 lebih kecil dari signifikansi $(\alpha=0,05)$. Hipotesis pada penelitian ini yang menyatakan bahwa pelatihan dapat mempengaruhi kinerja penyuluh pertanian dinyatakan diterima.

Pada masa pandemi COVID-19, pemerintah memberlakukan PSBB yang membuat penyuluh pertanian sulit untuk berinteraksi dengan petani secara langsung. Pada kondisi ini, penyuluh harus dapat menyesuaikan diri agar tetap dapat mendampingi petani. Salah satu cara untuk melakukan kegiatan penyuluhan adalah dengan bantuan media elektronik. Pelatihan penyuluh pertanian seperti pelatihan IT sangat membantu penyuluh pertanian dalam memanfaatkan teknologi untuk tetap dapat bekerja walaupun dengan metode pertanian tidak langsung.

5) Pengaruh ketersediaan sarana prasarana $\left(X_{5}\right)$ terhadap kinerja penyuluh pertanian

Hasil uji parsial pada Tabel 6 menunjukkan bahwa variabel ketersediaan sarana prasarana secara parsial berpengaruh nyata terhadap kinerja penyuluh pertanian di Provinsi DKI Jakarta. Hal ini dibuktikan dengan nilai p-value sebesar 0,010 lebih kecil dari signifikansi $(\alpha=0,05)$. Hipotesis pada penelitian ini yang menyatakan bahwa ketersediaan sarana prasarana dapat mempengaruhi kinerja penyuluh pertanian dinyatakan diterima.

Pada masa pandemi COVID-19 dengan diberlakukannya PSBB di Provinsi DKI Jakarta, ketersediaan sarana dan prasarana menjadi suatu hal penting bagi penyuluh pertanian untuk melakukan kegiatan penyuluhan secara tidak langsung. Kondisi demikian membuktikan bila ketersediaan sarana dan prasarana meningkat maka kinerja penyuluh 
pertanian juga akan ikut meningkat. Kementerian Pertanian melalui BPPSDMP pada tahun 2020 mulai memprioritaskan dukungan sarana dan prasarana untuk penyuluh pertanian dengan tujuan untuk meningkatkan peran penyuluh di era teknologi 4.0.

6) Pengaruh kondisi lingkungan kerja $\left(\mathrm{X}_{6}\right)$ terhadap kinerja penyuluh pertanian

Hasil uji parsial pada Tabel 6 menunjukkan bahwa variabel kondisi lingkungan kerja secara parsial berpengaruh nyata terhadap kinerja penyuluh pertanian di Provinsi DKI Jakarta. Hal ini dibuktikan dengan nilai $p$-value sebesar 0,023 lebih kecil dari signifikansi ( $\alpha$ $=0,05)$. Hipotesis pada penelitian ini yang menyatakan bahwa kondisi lingkungan kerja dapat mempengaruhi kinerja penyuluh pertanian dinyatakan diterima.

\section{d. Uji Determinasi $\left(\mathbf{R}^{2}\right)$}

Koefisien determinasi merupakan pengujian yang dilakukan untuk mengitung pengaruh variabel independen terhadap variabel dependen. Nilai $\mathrm{R}^{2}$ menunjukkan seberapa besar pengaruh variabel independen yakni umur $\left(\mathrm{X}_{1}\right)$, pengalaman $\left(\mathrm{X}_{2}\right)$, pendidikan $\left(\mathrm{X}_{3}\right)$, pelatihan $\left(\mathrm{X}_{4}\right)$, ketersediaan sarana dan prasarana $\left(\mathrm{X}_{5}\right)$, dan lingkungan kerja $\left(\mathrm{X}_{6}\right)$ terhadap variabel dependen yakni kinerja penyuluh pertanian pada masa PSBB (Y). Nilai $\mathrm{R}^{2}$ dapat dilihat pada Tabel 7 berikut.

Tabel 7 Hasil Model Summary Koefisien Determinasi

\begin{tabular}{cccc}
\hline \hline $\mathbf{R}$ & R Square & Adjusted $\boldsymbol{R}$ Square & $\begin{array}{c}\text { Std. Error of the } \\
\text { Estimate }\end{array}$ \\
\hline 0,725 & 0,525 & 0,442 & 2,913 \\
\hline \hline
\end{tabular}

Sumber: Analisis Data Primer

Berasarkan Tabel 5.19 menunjukkan bahwa nilai $\mathrm{R}_{2}$ adalah 0,525. Hal ini menunjukkan bahwa umur $\left(\mathrm{X}_{1}\right)$, pengalaman $\left(\mathrm{X}_{2}\right)$, pendidikan $\left(\mathrm{X}_{3}\right)$, pelatihan $\left(\mathrm{X}_{4}\right)$, ketersediaan sarana dan prasarana $\left(\mathrm{X}_{5}\right)$, dan lingkungan kerja $\left(\mathrm{X}_{6}\right)$ dapat memengaruhi kinerja penyuluh pertanian selama diberlakukannya PSBB sebesar 52,5\%. Sisanya yakni 47,5\% dipengaruhi oleh variabel lain yang tidak diletili dalam penelitian ini.

\section{Kesimpulan}

Berdasarkan penelitian yang dilakukan, maka dapat diberikan beberapa kesimpulan, yaitu kinerja penyuluh pertanian di Provinsi DKI Jakarta selama diberlakukannya PSBB berada dalam kategori baik. Umur, masa kerja, pendidikan, pelatihan, ketersediaan sarana dan prasarana, dan lingkungan kerja secara bersama-sama berpengaruh signifikan terhadap kinerja penyuluh pertanian selama diberlakukannya PSBB. Secara parsial umur dan masa kerja tidak berpengaruh terhadap kinerja penyuluh, sedangkan pendidikan, pelatihan, ketersediaan sarana dan prasarana, dan lingkungan kerja secara parsial berpengaruh signifikan terhadap kinerja penyuluh pertanian selama diberlakukannya PSBB di Provinsi DKI Jakarta. Kinerja penyuluh pertanian selama diberlakukannya PSBB di Provinsi DKI Jakarta 52,50\% dipengaruhi oleh umur, pengalaman, pendidikan, pelatihan, ketersediaan sarana dan prasarana, dan lingkungan kerja, sedangkan 42,50\% lainnya dipengaruhi oleh faktor lain yang tidak diteliti. 
Pengaruh Kebijakan Pembatasan Sosial Berskala Besar (PSBB) Terhadap Kinerja Penyuluh Pertanian di Provinsi DKI Jakarta 


\section{Bibliografi}

Anggrahita, H., \& Guswandi, G. (2018). Keragaman Fungsi dan Bentuk Spasial Pertanian Kota (Studi Kasus: Pertanian Kota di Jakarta). Jurnal Wilayah Dan Lingkungan, 6(3), $148-163$.

Arwati, S. (2018). Pengantar Ilmu Pertanian Berkelanjutan. Makassar: CV. Inti Mediatama.

Bahua, M. I. (2016). Kinerja Penyuluh Pertanian. Deepublish.

Duli, N. (2019). Metodologi Penelitian Kuantitatif: Beberapa konsep dasar untuk penulisan skripsi \& analisis data dengan SPSS. Deepublish.

Effendi, S., \& Singarimbun, M. (1995). Metode penelitian survai.

Emanuel EJ, Persad G, Upshur R, Thome B, Parker M, Glickman A, Zhang C, Boyle C, Smith M, Phillips JP. (2020). Fair Allocation f Scarce Medical Resources in the Time of Covid-19. The New England Journal of Medicine Vol. 382(21) : 2049-2055.

Muharsini, S., \& Tiesnamurti, B. (2017). Peraturan Menteri Pertanian Republik Indonesia Nomor 36/Permentan/LB. 070/8/2016 tentang Pengkajian Keamanan Pakan Produk Rekayasa Genetik. Prosiding Seminar Nasional Teknologi Peternakan Dan Veteriner, 28-36.

Peraturan Menteri Pertanian Republik Indonesia Nomor 91/Permentan/OT.140/9/2013 Tentang Pedoman Evaluasi Kinerja Penyuluh Pertanian.

Purwatiningsih, NA, Fatchiya A, Mulyandari RS. 2018. Pemanfaatan Internet dalam Meningkatkan Kinerja Penyuluh Pertanian di Kabupaten Cianjur. Jurnal Penyuluhan. Vol. 14(1): 79-91.

Pusat Penelitian dan Pengembangan Perkebunan. (2020). COVID-19: Peluang dan Dampak terhadap Sektor Pertanian. url: http://perkebunan.litbang.pertanian.go.id/covid-19peluang-dan-dampak-terhadap-sektor-pertanian/

Rahmawati, R., Baruwadi, M., \& Bahua, M. I. (2019). Peran kinerja penyuluh dan efektivitas pelaksanaan penyuluhan pada program intensifikasi jagung. Jurnal Sosial Ekonomi Pertanian, 15(1), 56-70.

Sasakawa Africa Association. (2020). Assesment of the Impact of COVID-19 on Food Systems in Africa and Recommended Mitigation Measures. url: https://www.saasafe.org/newsfiles/files/Assessment of the Impact of COVID-19.pdf

Situmeang, T. (2020). Keberadaan Denda Administratif Terkait Peraturan Gubernur Dki Jakarta Nomor 33 Tahun 2020 Tentang Pelaksanaan Psbb Dalam Penanganan Covid-19 Di Provinsi Dki Jakarta. To-Ra, 6(2), 156-169.

Sugiyono. (2018). Metode Penelitian Kuantitafif. Alfabeta.

Sutrisno, S. (2016). Kinerja Penyuluh Pertanian dalam Memberdayakan Petani. Jurnal Litbang: Media Informasi Penelitian, Pengembangan Dan IPTEK, 12(1), 69-80. 
Pengaruh Kebijakan Pembatasan Sosial Berskala Besar (PSBB) Terhadap Kinerja Penyuluh Pertanian di Provinsi DKI Jakarta

Wibowo HT \& Haryanto Y. (2020). Kinerja Penyuluh Pertanian Dalam Masa Pandemi Covid-19 di Kabupaten Magelang. Jurnal Penelitian Peternakan Terpadu Vol. 2(2) : 72-92. 